J. Lake Sci. (湖泊科学) , 2016, 28(2): 421-431

DOI 10. 18307/2016. 0223

(c) 2016 by Journal of Lake Sciences

\title{
考虑采砂影响的鄱阳湖丰水期悬浮泥沙浓度模拟”
}

\author{
李海军 ${ }^{1}$, 陈晓玲 ${ }^{1,2,3}$, 陆建忠 ${ }^{* * *}$, 张 鹏 $^{4}$, 齐亭达 ${ }^{1}$, 陈莉琼 ${ }^{1}$ \\ (1: 武汉大学测绘遥感信息工程国家重点实验室,武汉 430079) \\ (2: 地球空间信息技术协同创新中心,武汉 430079) \\ (3: 江西师范大学鄱阳湖湿地与流域研究教育部重点实验室,南昌 330022) \\ ( 4 : 水利部中国科学院水工程生态研究所,水利部水工程生态效应与生态修复重点实验室,武汉 430079)
}

摘 要: 针对受采砂活动影响显著的鄱阳湖高浑浊水体,结合数值模拟和遥感技术,利用已有的鄱阳湖采砂区遥感监测 结果, 在构建的鄱阳湖水动力-悬浮泥沙输移模型中添加泥沙点源, 对 2011 年 7月 1-31 日采砂影响下的鄱阳湖丰水期 悬浮泥沙浓度进行数值模拟. 利用悬浮泥沙浓度实测数据和 MODIS 影像反演结果对模拟结果的有效验证表明, 考虑采砂 影响后, 悬浮泥沙浓度模拟值与实测值具有强相关关系, 确定性系数为 0.831 , 均方根误差为 $15.5 \mathrm{mg} / \mathrm{L}$, 悬浮泥沙浓度空 间分布趋势与遥感反演结果基本一致. 模拟结果显示, 采砂活动对鄱阳湖南部主湖区、河流人湖口影响较小, 其主要影响 由南向北, 经棠荫以西和松门山岛以北航道、入江水道延伸到湖口区域, 是鄱阳湖北湖区高浑浊水体形成的重要原因.

关键词: 数值模拟; 悬浮泥沙; 遥感; Delft3D; 鄱阳湖

\section{Numerical simulation of suspended sediment concentration in Lake Poyang during flood season considering dredging activities}

LI Haijun ${ }^{1}$, CHEN Xiaoling ${ }^{1,2,3}$, LU Jianzhong ${ }^{1 * *}$, ZHANG Peng ${ }^{4}$, QI Hengda ${ }^{1} \&$ CHEN Liqiong ${ }^{1}$

(1: State Key Laboratory of Information Engineering in Surveying, Mapping and Remote Sensing, Wuhan University, Wuhan 430079, P.R. China)

(2: Collaborative Innovation Center of Geospatial Technology, Wuhan 430079, P.R. China)

(3: Key Laboratory of Lake Poyang Wetland and Watershed Research, Ministry of Education, Jiangxi Normal University, Nanchang 330022, P.R. China)

(4: Key Laboratory of Ecological Impacts of Hydraulic-Projects and Restoration of Aquatic Ecosystem of Ministry of Water Resource, Institute of Hydroecology, Ministry of Water Resource and Chinese Academy of Science, Wuhan 430079, P.R.China)

Abstract: Numerical simulation and remote sensing are used in suspended sediment concentration simulation during flood season in
Lake Poyang, in which water turbidity is highly affected by dredging activities. With the aid of Landsat ETM+ images, the location
of main dredging areas and ships are detected. Several sediment point sources are added in dredging areas in the Delft3D model to
simulate the suspended sediment concentration including the effects of dredging of Lake Poyang from July 1,2011 to July 31 ,
2011. Taking in-situ data and suspended sediment concentration retrieved from MODIS images as validation data, there is a good
consistence between the simulating and validating results, with $R^{2}$ of 0.831 , a root-mean-square error of $15.5 \mathrm{mg} / \mathrm{L}$ and a consist-
ent spatial pattern of suspended sediment concentration compared with suspended sediment concentration retrieved from MODIS im-
ages. It also shows less dredging effects in the southern main lake and river inlets but more in the northern from channel in the west
of Tangyin and the north of Songmen Mountain, water-way in the northern and the lake outlet, which is one of the main reasons

* 国家自然科学基金项目 (41331174,41101415,41301366)、湖北省自然科学基金项目(2015CFB331)、江西省重大生 态安全问题监控协同创新中心专项 (JXS-EW-08)、测绘地理信息公益性行业科研专项(201512026) 和国家科技支 撑计划项目 (2012BAC06B04) 联合资助. 2014-12-23 收稿; 2015-06-08 收修改稿. 李海军(1992 ), 男, 硕士; E-mail:lihaijun0629@gmail.com.

** 通信作者;E-mail:lujzhong@whu.edu.cn. 
causing high turbidity water in Lake Poyang. This study shows that by making good use of in-situ data and satellite remote sensing images, the precision of numerical simulation of suspended sediment concentration can be increased by considering the effect of human dredging activities, thus provided a good method for human affected water environment simulations of lakes.

Keywords: Numerical simulation; suspended sediment concentration; remote sensing; Delft3D; Lake Poyang

悬浮泥沙携带大量的营养盐和重金属等污染物, 其能改变水体透光性, 是水环境变化的重要影响因子, 对水环境生态系统有着重大影响 ${ }^{[1]}$. 采砂活动极大地影响着悬浮泥沙时空变化, 从而影响水环境. 现有的水 体悬浮泥沙研究大多依靠数值模拟 ${ }^{[2-5]}$ 或遥感技术 ${ }^{[6-7]}$, 两者结合的研究则主要以海岸带、河口和湖泊的水 动力、水质营养盐和泥沙模拟为主 ${ }^{[8-11]}$. 对于内陆湖泊, 尤其是针对受采砂活动影响显著的鄱阳湖高浑浊水 体来说,结合遥感技术, 对采砂活动影响下的悬浮泥沙数值模拟鲜有研究.

自 2001 年长江河道采砂被禁止后, 鄱阳湖采砂业迅速兴起. 此后 10 余年间, 除 2008 年曾禁采外, 鄱阳 湖采砂活动不断, 湖泊悬浮泥沙浓度显著上升,引发一系列环境问题 ${ }^{[12]}$. 由于鄱阳湖复杂的水环境特性, 水 沙时空格局变化剧烈, 水环境的精确数值模拟研究一直是难题. 部分学者建立鄱阳湖流域的水文水动力模 型, 对湖泊水动力、水质、氮磷营养盐以及鄱阳湖水利枢纽工程的影响进行模拟研究 ${ }^{[13-17]}$. 针对采砂问题, 现 有的数值模拟主要集中在河流航道疏浚、港口工程以及海岸带人工造陆与倾沙等方面 ${ }^{[18-21]}$. 对于鄱阳湖采 砂问题, 一些学者利用遥感技术, 建立鄱阳湖水体透明度或悬浮泥沙浓度与采砂船只数目之间的关系, 分析 采砂影响范围与泥沙收支平衡 ${ }^{[22-24]}$. 也有学者利用 MODIS 影像反演悬浮泥沙, 对数值模型进行初始化和参 数率定, 间接考虑采砂影响 ${ }^{[25]}$. 通过建立相关关系、间接模拟的方法只能粗略地估算采砂影响, 难以针对鄱 阳湖采砂活动对悬浮泥沙的影响进行连续、直观和准确的分析.

本文针对鄱阳湖高浑浊水体受采砂活动影响显著的特点, 借助数值模型对水动力过程、悬浮泥沙输移 进行连续模拟的优势, 利用采砂区遥感影像监测结果, 通过在模型中添加泥沙点源的方法考虑采砂活动影 响, 对鄱阳湖丰水期悬浮泥沙进行数值模拟, 以期更精确地模拟悬浮泥沙, 为采砂活动影响下水沙时空变化 及其生态效应等进一步研究奠定基础.

\section{1 研究区域与数据}

鄱阳湖 $\left(28^{\circ} 22^{\prime} \sim 29^{\circ} 45^{\prime} \mathrm{N}, 115^{\circ} 47^{\prime} \sim 116^{\circ} 45^{\prime} \mathrm{E}\right)$ 地处江西省北部, 长江中下游南岸, 是我国最大的淡水湖 泊. 以松门山为界, 鄱阳湖被分为南北 2 部分, 北面为人江水道, 长约 $40 \mathrm{~km}$, 最窄处约 $2.8 \mathrm{~km}$; 南面为主湖 区,长约 $133 \mathrm{~km}$, 最宽处达 $74 \mathrm{~km}$. 鄱阳湖主要承接修水、赣江、抚河、饶河 (分支为乐安河和昌江)、信江“五 河” 以及博阳河、漳河来水, 经调蓄后由湖口汇人长江, 是一个过水性、吞吐型、季节性的大型通江湖泊 (图 1a). 受人湖来水和长江的双重影响,鄱阳湖水情复杂, 水沙格局时空变化剧烈.

本文选取 2011 年 7 月 1-31 日时间段对鄱阳湖丰水期水动力及悬浮泥沙进行数值模拟. 研究涉及的数 据主要包括: (1) 鄱阳湖及其流域水文数据: 修水的虬津站和万家埠站、赣江的外洲站、抚河的李家渡站、信 江的梅港站、乐安河的虎山站和昌江的渡峰坑站以及湖口站的日均流量和泥沙含量数据; 星子、都昌、棠荫、 湖口 4 个水文站的日均水位数据; 鄱阳湖湖底高程以及鄱阳湖附近波阳气象站的风速、风向等气象数据. (2) 现场观测数据: 2011 年 7 月 15-23 日鄱阳湖野外观测的 50 个站点 (图 1b) 悬浮泥沙浓度数据. (3) 遥感 影像数据: 从美国国家航空航天局 NASA 网站 (http:// ladsweb. nascom. nasa. gov/data/search. html) 下载的 2011 年 7 月 1-31 日鄱阳湖区无云或少云 MODIS 影像 $250 \mathrm{~m}$ 分辨率地表反射率产品 MOD09GQ; 从美国地 质调查局 USGS 网站 (http: // earthexplorer. usgs. gov/) 下载的 2011 年 7 月 4 日鄱阳湖区 Landsat ETM+清晰 影像,利用 ENVI 去除影像条带.

\section{2 研究方法}

\section{1 MODIS 影像水体提取与悬浮泥沙反演}

对 MODIS 影像进行云掩膜后 ${ }^{[26]}$, 采用归一化植被指数 NDVI (normalized difference vegetation index) 阈值 法进行水体提取 ${ }^{[27]}$, 根据水体光谱特性, 选取 $N D V I<0$ 作为水体的判断条件. 根据水体像元个数和分辨率计 


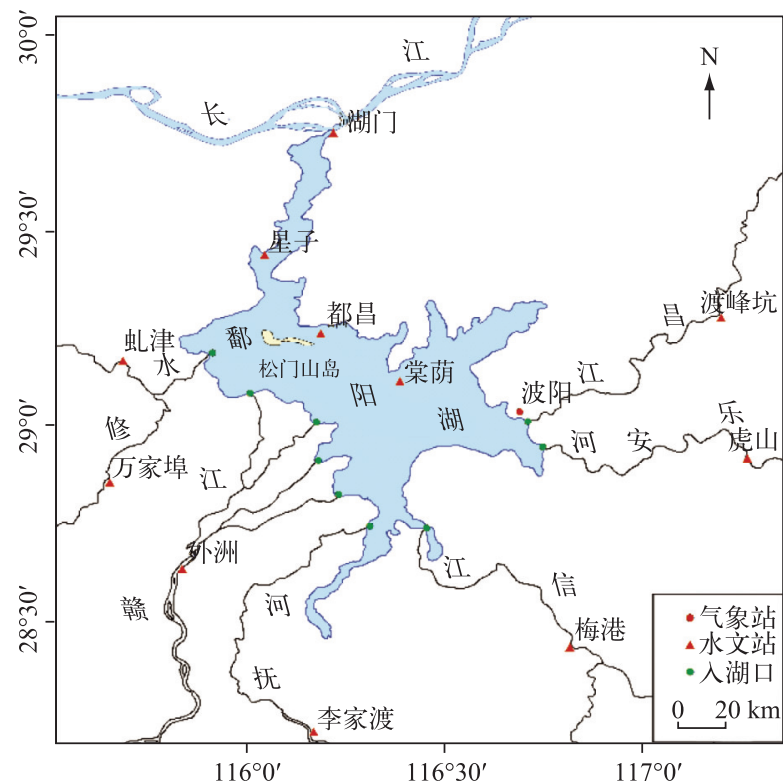

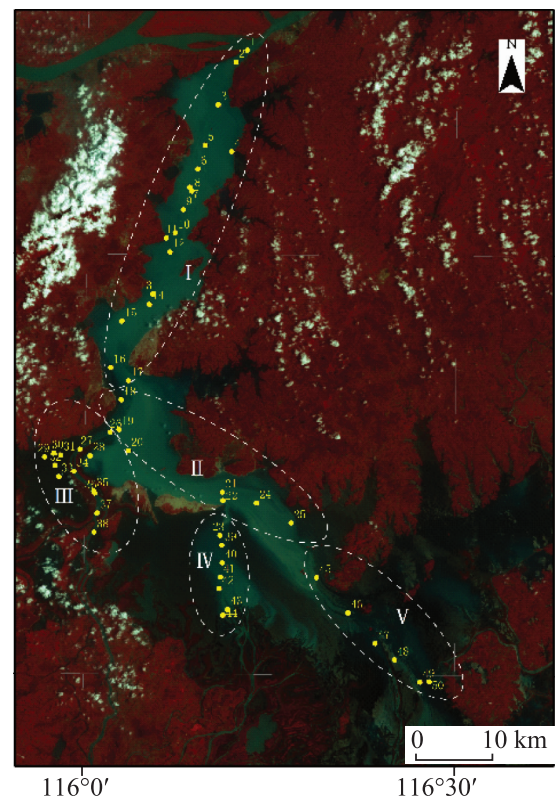

图 1 研究区域: (a) 鄱阳湖地理位置和相关水文站、气象站; (b) 2011 年 7 月 $15-23$ 日鄱阳湖采样点

(HJ1B-CCD1 影像, RBG :432,2011 年 7 月 21 日)

Fig.1 Study area: (a) location of Lake Poyang and main hydrologic stations, meteorological station; (b) In-situ stations in Lake Poyang from July 15, 2011 to July 23, 2011 (HJ1B-CCD1 image, RGB:432, July 21, 2011)

算水体面积,将水体范围矢量化后得到鄱阳湖水体边界. 考虑到反演模型的区域性和精度,采用文献 [28]的 指数模型反演鄱阳湖悬浮泥沙浓度.

\section{2 鄱阳湖悬浮泥沙输移数值模型构建}

本文选取荷兰 Delft3D 水动力模型中的 Delft3D-Flow 对 2011 年 7 月 1-31 日鄱阳湖丰水期水动力和悬 浮泥沙进行数值模拟. Delft3D-Flow 采用正交曲线网格,其数值格式基于有限差分法采用 ADI 时间积分 ${ }^{[29]}$. 其耦合了泥沙模块, 可以有效模拟风场驱动下的非恒定流, 在模拟水位、面积和流速等水动力条件的同时, 对泥沙输移进行同步模拟.

2.2. 1 计算网格 由于 2011 年 7 月 1 日没有鄱阳湖区无云 MODIS 影像, 分析水文数据得知,都昌站 2011 年 6月 20-30日实测水位均高于模拟时间段内水位, 因此采用 2011 年 6 月 27 日 MODIS 无云影像, 提取鄱阳 湖区水体范围, 剔除湖区周边未与主湖连通的水域, 以鄱阳湖水体边界为模拟范围. 采用矩形网格对模拟范 围进行网格划分. 考虑到计算机性能和数值模型计算收玫性的要求, 网格尺寸大小约为 $300 \sim 500 \mathrm{~m}$, 将湖底 高程插值到网格,生成模型所需地形数据(图 2).

2.2 .2 边界条件和初始条件 模型边界条件为修水、赣江、抚河、信江、饶河人湖流量和悬浮泥沙浓度. 修水、 抚河、信江各设置 1 个人湖口, 饶河分为昌江和乐安河 2 支各设 1 个人湖口, 人湖流量和悬浮泥沙浓度采用 各站点日均数据; 赣江设置 4 个人湖口, 其中西支在吴城附近入湖, 另外 3 支在鄱阳湖西南部入湖, 赣江总支 人湖流量和悬浮泥沙浓度采用外洲站日均数据, 根据外洲站流量设定动态分流比 ${ }^{[30]}$, 计算 4 个分支人湖口 的流量和悬浮泥沙浓度. 以鄱阳湖流人长江湖口为开边界, 开边界水位为湖口站日均水位, 开边界悬浮泥沙 浓度采用 Neumann 边界条件 ${ }^{[31]}$. 模型考虑风场影响, 采用波阳气象站实测风速及风向数据, 作为整个湖区 统一的风应力条件. 模型采用 1 个月的热启动, 不考虑水文站至河流入湖口的水量变化, 以各水文站实测数 据作为边界条件; 以主湖区内都昌站 2011 年 6 月 1 日实测水位作为初始水位,初始悬浮泥沙浓度和初始流 速均设为 0 ,对 2011 年 7 月 $1-31$ 日的模拟结果进行分析.

2. 2.3 其他参数 模拟计算的时间步长为 $5 \mathrm{~min}$, 其他参数如底部糙率、临界水深、粘滞系数、泥沙沉降速度、 
泥沙沉降临界剪切力、泥沙侵蚀沉降剪切力、侵蚀常量等参照文献 $[25]$ 给定值进行设置.
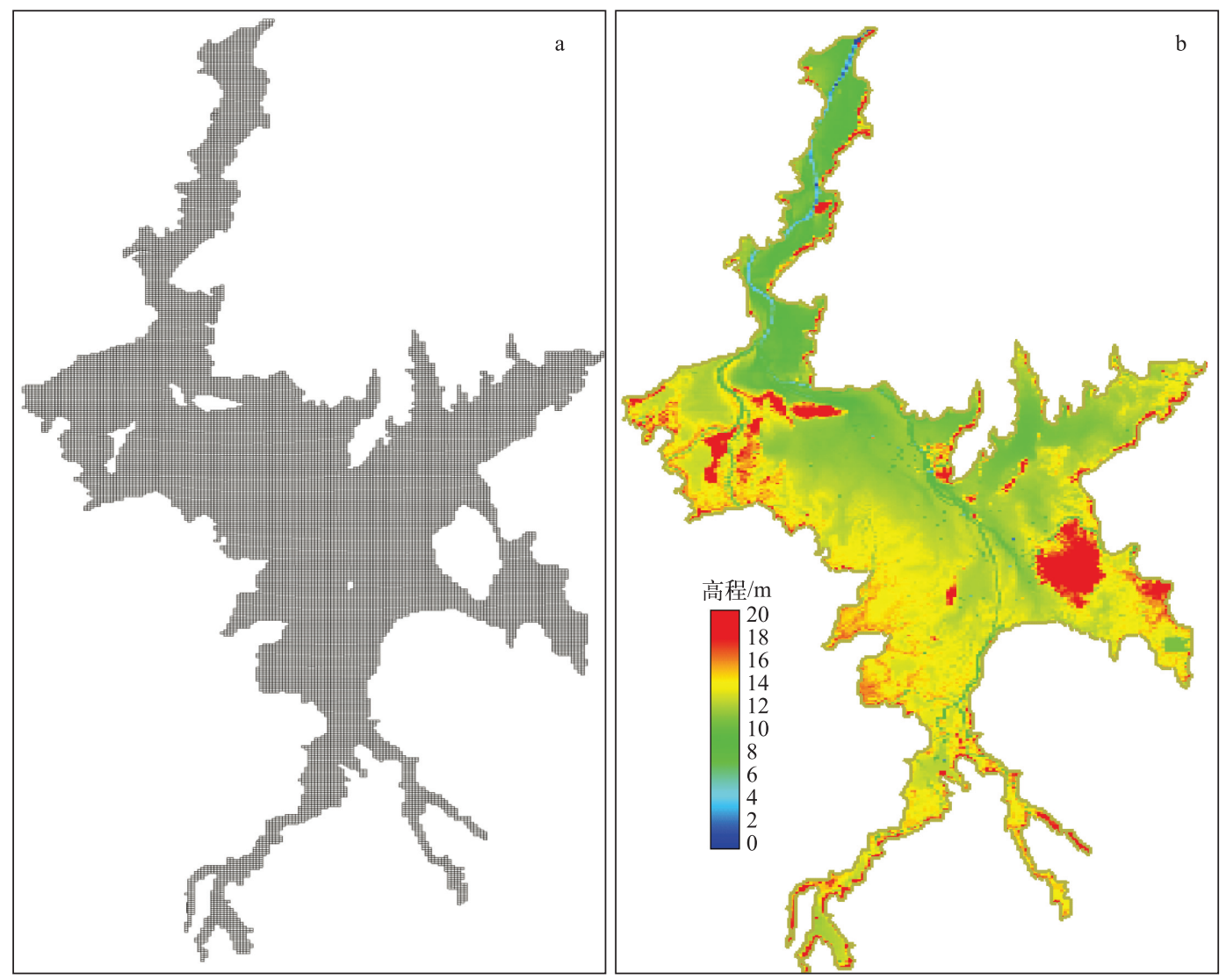

图 2 鄱阳湖计算网格 (a) 和湖底高程示意 (b)

Fig. 2 Computational grids( a) and bottom elevation( b) of Lake Poyang

\section{3 考虑采砂活动的鄱阳湖悬浮泥沙浓度模拟}

(1) 不考虑采砂的悬浮泥沙模拟: 模型配置和上文描述的一致. (2) 考虑采砂的悬浮泥沙模拟:2011 年 7 月 15-23 日鄱阳湖现场观测时发现多个采砂作业区. 根据 $\mathrm{Li}$ 等 ${ }^{[32]}$ 的算法,采用 2011 年 7 月 4 日鄱阳湖 Landsat ETM+影像对采砂船进行监测, 确定 3 个主要采砂区, 分别位于松门山岛以北(图 3A)、松门山岛以东 (图 3B) 和棠荫以西 (图 3C). 根据 Pennekamp 等 ${ }^{[33]}$ 的研究, 采砂效率 $5500 \mathrm{~m}^{3} / \mathrm{h}$ 的采砂船, 采砂中心悬浮泥 沙浓度约为 $150 \mathrm{mg} / \mathrm{L}$. 根据现场观测资料, 鄱阳湖采砂船的采砂效率一般为 $10000 \mathrm{~m}^{3} / \mathrm{h}$, 其外围表层水体的 悬浮泥沙浓度达到 $277.4 \mathrm{mg} / \mathrm{L}$, 因此取采砂中心悬浮泥沙浓度约为 $300 \mathrm{mg} / \mathrm{L}$. 遥感影像解译的结果中, 剔除 航道内运砂船后, A、B、C 采砂区内采砂船数目分别为 $5 、 4 、 8$. 考虑到计算网格尺寸较大、同一个网格内存在 多艘采砂船的情况, 对模型适当简化. 分别以 1 个泥沙点源代替各采砂区内多艘采砂船的共同影响,则 A、 B、C 采砂区内的泥沙点源浓度分别为 $1500 、 1200$ 和 $2400 \mathrm{mg} / \mathrm{L}$, 符合 2011 年丰水期 A、B、C 主要采砂区的采 砂强度差异规律 ${ }^{[32]}$. 由于采砂船一般长时间定点作业, 本文假设在整个模拟时间段内, 采砂船的位置不发 生变化,按照每天 8:00 至 18:00 工作 $10 \mathrm{~h}$,模拟采砂活动对悬浮泥沙浓度的影响.

选取 2011 年 7 月 4 日和 7 月 20 日 2 景 MODIS 无云或少云影像反演悬浮泥沙浓度, 与最接近 MODIS 过 境时间的悬浮泥沙模拟结果进行对比. 根据鄱阳湖由南向北的流场规律和地理位置特征, 选取 5 个兴趣点 (图 3), 分析其在不同情景下悬浮泥沙浓度变化和采砂活动影响大小. 其中, a 点位于棠荫以西采砂区下游, 是鄱阳湖采砂活动的最上游; $\mathrm{b}$ 点位于松门山岛以北的狭窄航道内, 是鄱阳湖南北湖分界处; $\mathrm{c}$ 点位于鄱阳 
湖主湖区与人江水道的连通处, 鄱阳湖经此处汇人狭长的人江水道; $\mathrm{d}$ 点位于星子附近的人江水道内; $\mathrm{e}$ 点 位于湖口, 鄱阳湖经该处流人长江.
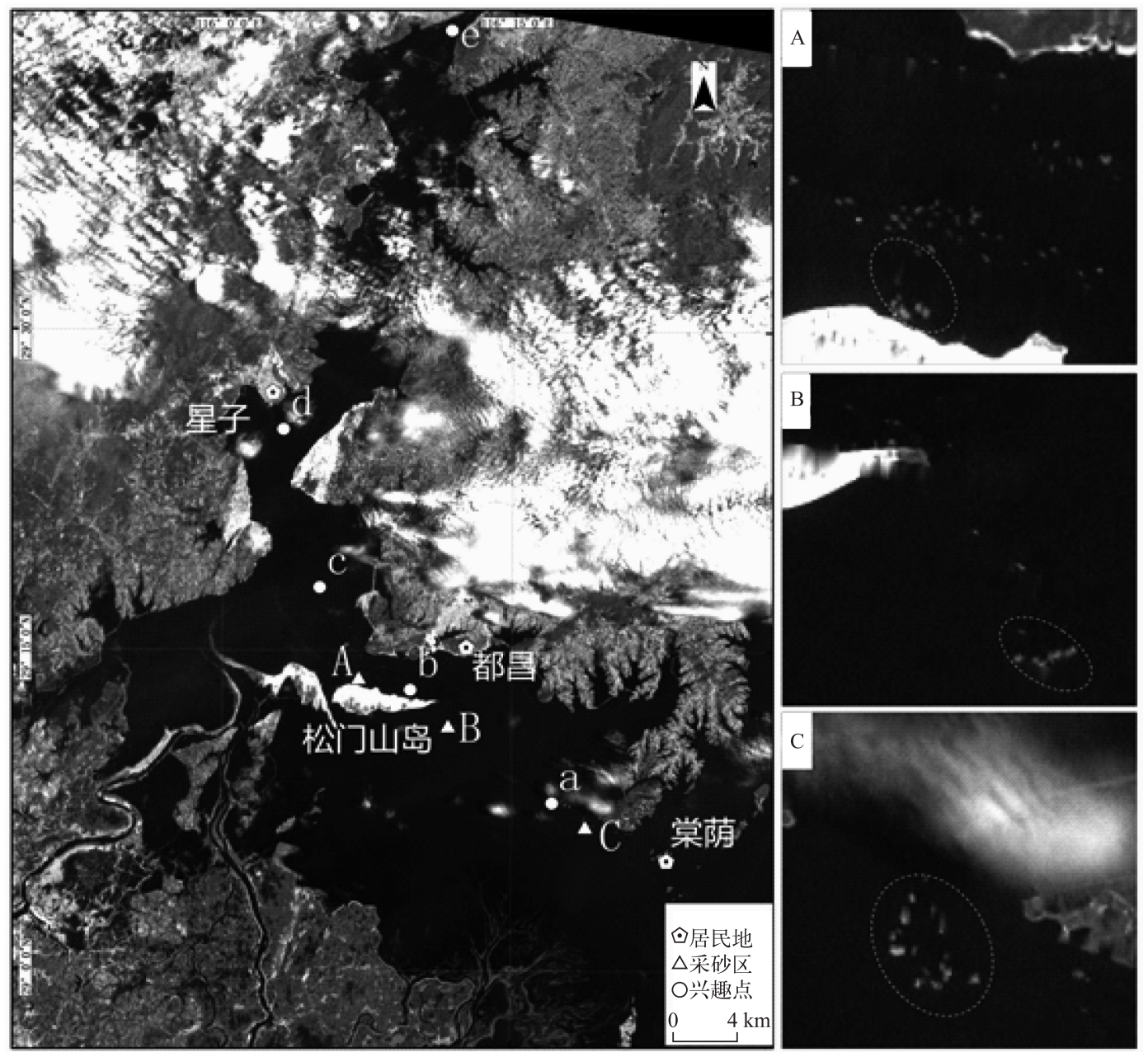

图 3 鄱阳湖 3 个主要采砂区和 5 个兴趣点 (Landsat ETM+第 7 波段, 2011 年 7 月 4 日)

Fig.3 Three main dredging areas and five interest points in Lake Poyang( Landsat ETM+, band 7, July 4, 2011)

\section{3 结果与讨论}

\section{1 鄱阳湖水动力模拟验证}

将星子、都昌、棠荫 3 个水文站的水位模拟值与实测值进行对比分析. 模拟时间段内 3 个站点水位模拟 值与实测值的均方根误差 (RMSE) 较小, $R M S E$ 均小于 $0.19 \mathrm{~m}$, 确定性系数 $R^{2}$ 在 0.98 以上(图 4). 不同位置 的 3 个站点水位模拟值与实测值比较吻合, 均与实测变化趋势一致. 同时间段 3 个站点的水位差异较小, 表 明鄱阳湖丰水期南北湖区水位梯度小,模型水位模拟精度较高.

由于水体面积精确值难以获取, 本文利用模拟时间段内鄱阳湖区 5 景 MODIS 无云或少云影像, 提取模 拟范围内水体面积, 对模拟结果进行验证. 鄱阳湖水体面积模拟值和 MODIS 影像提取值比较吻合, 多数日 期的模拟面积与影像提取面积相对误差在 $4 \%$ 以内,水体面积的变化趋势与水位验证趋势一致. 验证结果表 明本文选取 Delft3D 模型能够对鄱阳湖丰水期水环境进行较为准确的模拟 (表 1). 

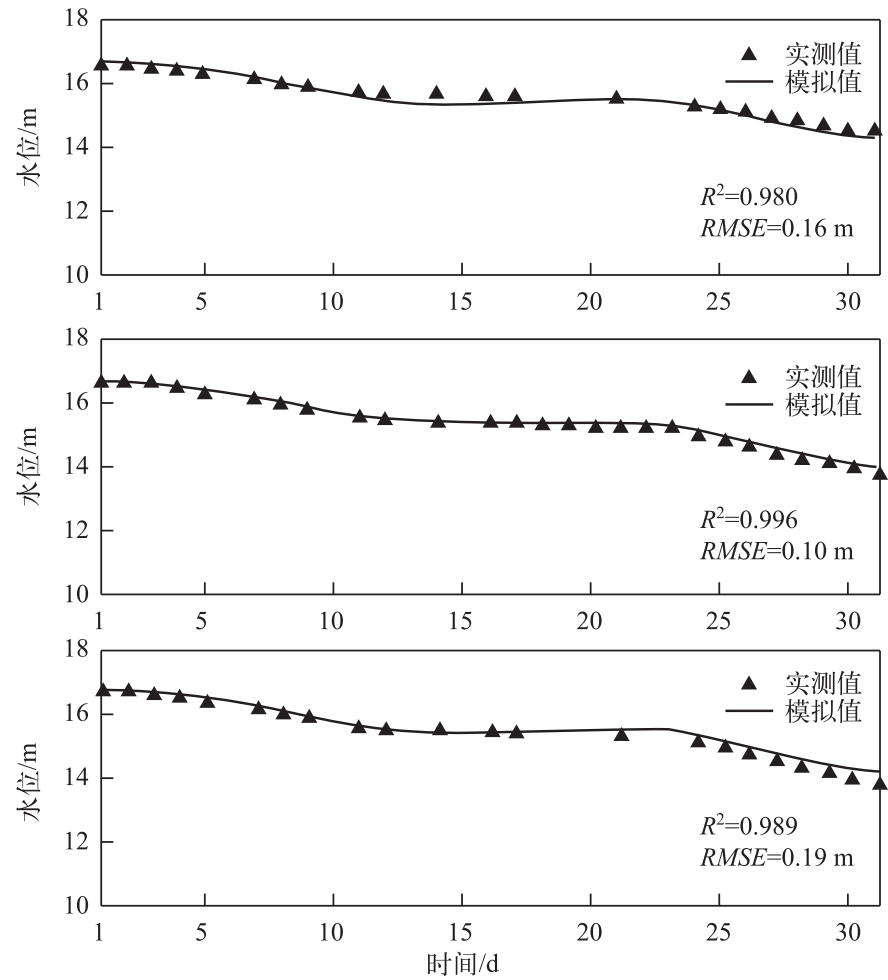

图 4 星子、都昌、棠荫水文站模拟水位与实测水位对比

Fig.4 Comparison of simulated and measured water level at Xingzi, Duchang and Tangyin Stations

表 1 水体面积模拟与 MODIS 影像提取值对比

Tab.1 Simulated water area and MODIS images extracted area

\begin{tabular}{cccc}
\hline 日期 & 水体面积模拟值 $/ \mathrm{km}^{2}$ & MODIS 影像提取值 $/ \mathrm{km}^{2}$ & 相对误差 $/ \%$ \\
\hline $2011-07-02$ & 2436.90 & 2457.51 & 0.84 \\
$2011-07-04$ & 2391.60 & 2315.52 & 3.29 \\
$2011-07-20$ & 2225.70 & 2147.81 & 3.63 \\
$2011-07-25$ & 1933.50 & 1912.92 & 1.08 \\
$2011-07-29$ & 1534.20 & 1652.54 & 7.16 \\
\hline
\end{tabular}

\section{2 采砂影响下的鄱阳湖悬浮泥沙浓度模拟结果分析}

分析不考虑采砂的鄱阳湖悬浮泥沙模拟结果发现, 模拟值与实测值之间相关性较差. 在 $18^{\#} 、 20^{\#} 、 24^{\#}$ 、 $25^{\#}$ 采样点处, 悬浮泥沙浓度实测值均超过 $100 \mathrm{mg} / \mathrm{L}$, 模拟值远小于实测值 (图 5). 由此可见, 若不考虑采砂 的影响, 鄱阳湖悬浮泥沙的浓度模拟结果很差, 精度不高. 考虑采砂影响后, 总的来说, 模拟值与实测值的变化 趋势比较一致, 二者数值上比较接近, $R^{2}$ 达到 0.831 , 均方根误差为 $15.5 \mathrm{mg} / \mathrm{L}$, 达到较高的模拟精度 (图 6).

不同位置采样点 (图 1) 的悬浮泥沙浓度呈现不同的变化规律. $1^{\#} \sim 17^{\#}$ 采样点位于 I 采样区人江水道, 悬浮泥沙随湖流汇集, 受采砂活动的综合影响, 泥沙浓度上升; 模拟值与实测值比较吻合. $18^{\#} \sim 25^{\#}$ 采样点位 于 II 采样区, 靠近 3 个主要采砂区, 受采砂影响较大; $18^{\#} 、 20^{\#}$ 采样点位于人江水道与主湖区连通处, 受较近 的 $\mathrm{A}$ 和 $\mathrm{B}$ 采砂区的双重影响, 悬浮泥沙浓度大幅增加; $24^{\#}$ 、2 $25^{\#}$ 采样点位于最大采砂强度的 $\mathrm{C}$ 采砂区下游, 受到的影响最大. 同样处于 II 采样区的 $21^{\#} 、 22^{\#} 、 23^{\#}$ 采样点均靠近 B 采砂区, 却呈现出不同的变化规律: 整 个模拟时间段内, 模型中都有采砂作业, 而样点采集时间不同, 实际情况中采砂作业可能中途停止, 导致 $21^{\text {\# }}$ 


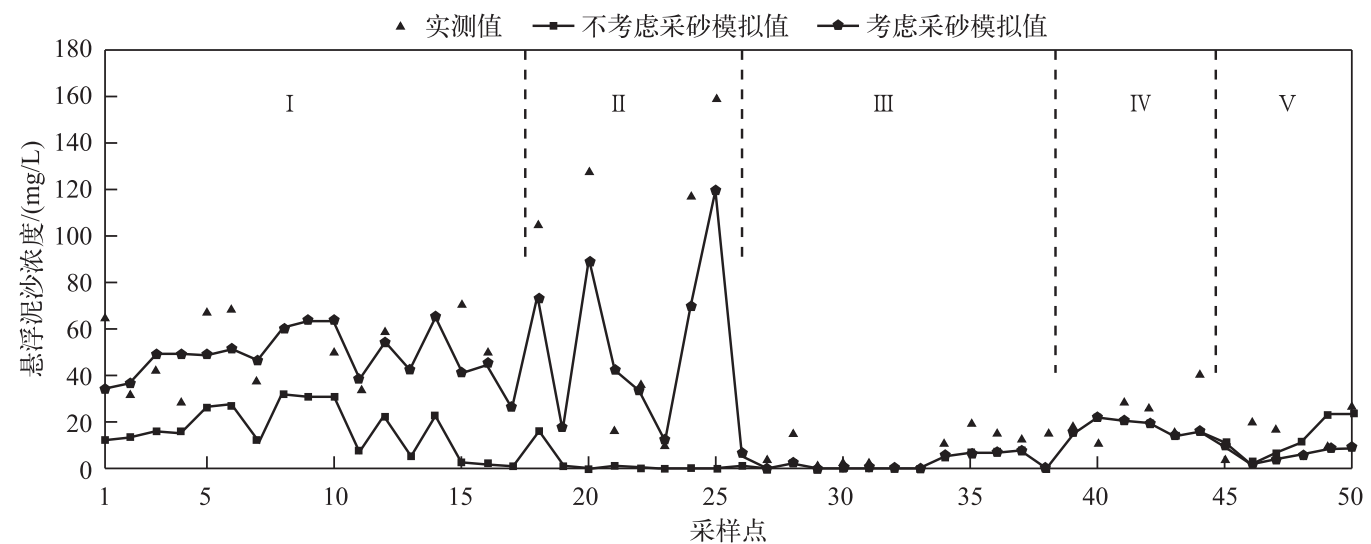

图 5 未考虑采砂模拟、考虑采砂模拟的悬浮泥沙浓度与实测值对比

Fig.5 Comparison of suspended sediment concentration between observed, simulated result with and without dredging

采样点模拟值高于实测值; 另外, 悬浮泥沙输移扩散 主要受湖流影响, 从 B 采砂区附近流场来说 (图 7), $23^{\#}$ 采样点位于 $\mathrm{B}$ 采砂区上游, 且 $\mathrm{B}$ 采砂区采砂强度 相对较小,该点受采砂影响较小; $22^{\#}$ 采样点受 B、C 采 砂区共同影响, 悬浮泥沙浓度上升. 对其他采样点而 言, III 采样区位于松门山岛以西的航道, 由于松门山 岛的阻隔, 采砂活动影响较小, 悬浮泥沙浓度模拟值 几乎没有变化; IV V V 采样区分别位于松门山岛以南 主湖区和鄱阳湖东部主湖区, 受下游采砂活动的影响 小, 悬浮泥沙浓度在 2 种情景下较为稳定一致.

\section{3 鄱阳湖采砂活动对悬浮泥沙分布的影响范围分析}

分别选取 2011 年 7 月 4 日和 2011 年 7 月 20 日 2 组不考虑采砂和考虑采砂的模拟结果与遥感反演结 果进行对比分析. 2 组鄱阳湖悬浮泥沙浓度空间分布 可以看出(图 8), 不考虑采砂和考虑采砂的模拟结果 存在较大差异. 不考虑采砂的结果中, 悬浮泥沙浓度 总体较低, 最高值约为 $80 \mathrm{mg} / \mathrm{L}$, 浓度相对较高的区域 主要集中在松门山岛北部以及北部人江水道. 考虑采 砂影响后, 悬浮泥沙浓度的空间分布更加合理, 其空 间相对变化趋势与 MODIS 遥感反演结果趋于一致. 在松门山岛以北、以东和棠荫以西的 3 个采砂区范围 内, 悬浮泥沙浓度明显上升, 人江水道的悬浮泥沙浓 度整体上升,总体呈现由南向北浓度由高到低的空间 分布趋势, 与遥感反演的结果比较一致. 2 组模拟结果 相隔时间较长, 存在比较一致的空间分布规律, 考虑 采砂模拟结果均优于不考虑采砂模拟结果. 2 组模拟 结果出现少部分区域异常高值的情况, 可能的原因是 模型在 3 个主要采砂区添加泥沙点源, 按照采砂效率 以及采砂强度设置泥沙点源浓度, 导致采砂中心的网 格点悬浮泥沙浓度值较高. 泥沙点源浓度的估算和设 Fig.7 Velocity field in dredging area B (July 18,2011)

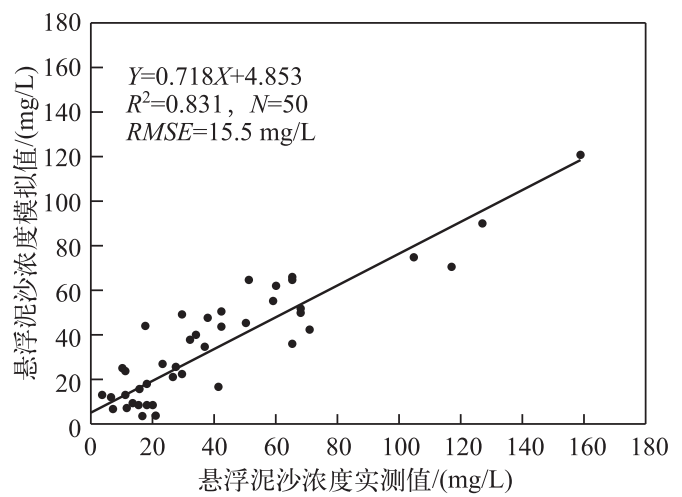

图 6 考虑采砂的悬浮泥沙浓度模拟值与 实测值的线性关系

Fig.6 Regression between in-situ suspended sediment concentration and simulated suspended sediment concentration with dredging

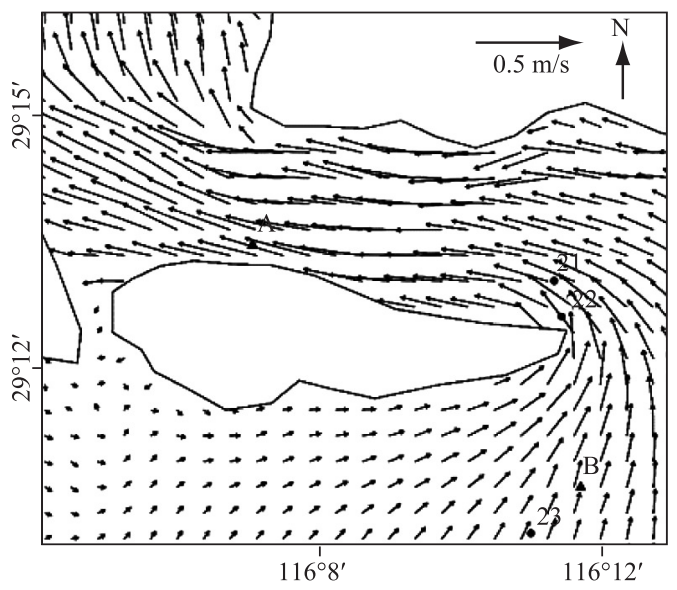

图 7 B 采砂区附近流场示意(2011 年 7 月 18 日) 
置误差可能导致异常高值的出现.
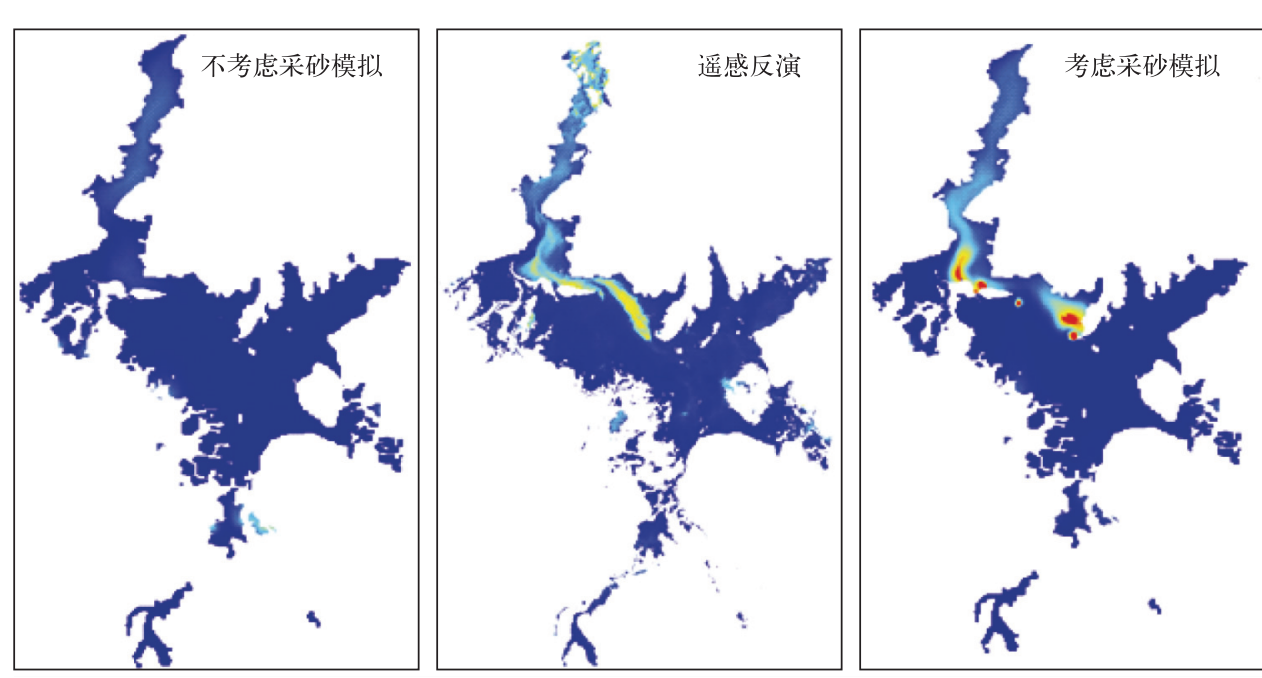

2011-07-04 悬浮泥沙浓度/ $(\mathrm{mg} / \mathrm{L})$ 240 220 200 180 160 140 120 100 80 60 40 20
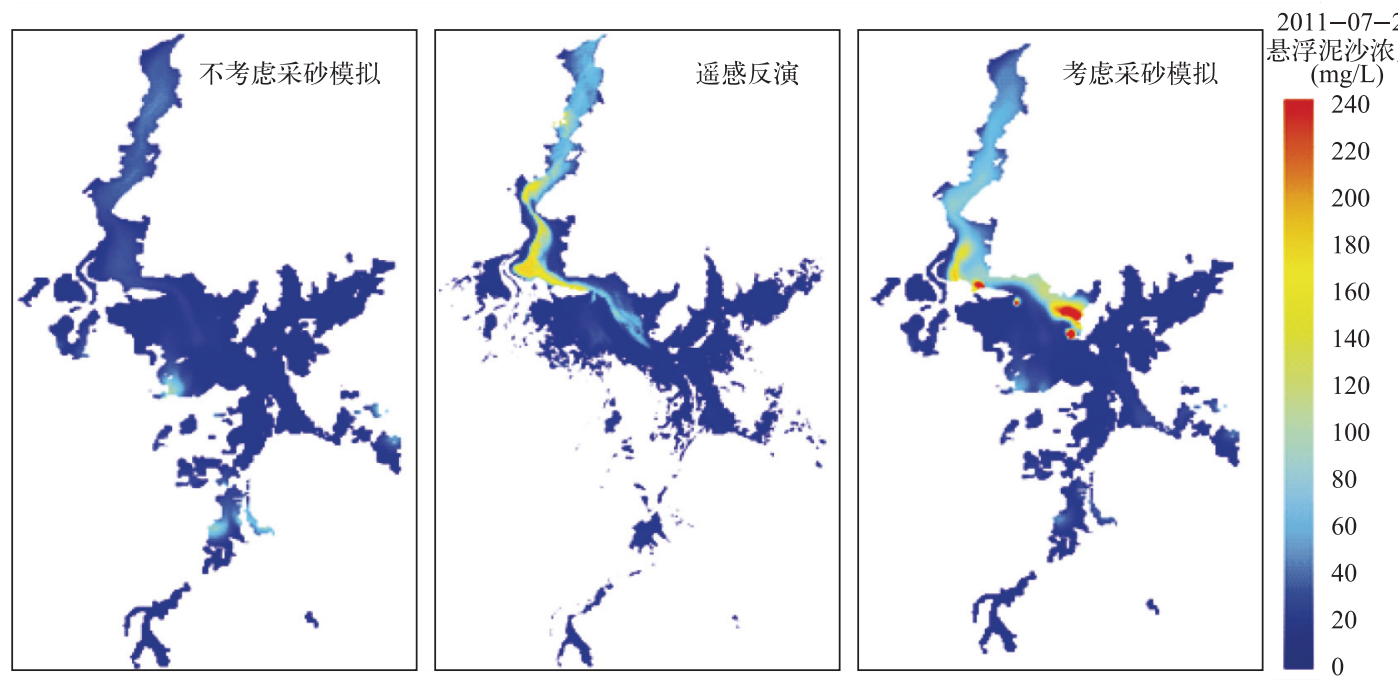

图 82011 年 7 月 4 日和 7 月 20 日鄱阳湖悬浮泥沙浓度空间分布

Fig.8 Spatial distribution of suspended sediment concentration on July 4 and July 20, 2011

5 个兴趣点悬浮泥沙浓度变化对比可以看出 (图 9), 整个模拟时间段内, 由于 “五河” 水沙的汇人和采砂 区影响, 同一个兴趣点悬浮泥沙浓度在不同情景下虽然有轻微波动, 但是总体上呈现基本一致的增加趋势. 不考虑采砂影响时, 5 个兴趣点悬浮泥沙浓度总体较低, 其中 $\mathrm{a}$ 兴趣点前 $20 \mathrm{~d}$ 悬浮泥沙浓度极低, 至模拟后 期也仅为 $40 \mathrm{mg} / \mathrm{L}$ 左右, 这与现场实测以及遥感反演的结果很不相符. 由此可见, 若不考虑采砂影响, 鄱阳 湖悬浮泥沙浓度模拟精度将受到极大影响. 考虑采砂影响后, 5 个兴趣点悬浮泥沙浓度增加, 反映出由南向 北采砂活动影响由强到弱的空间变化趋势: $\mathrm{a}$ 兴趣点受采砂强度最大的 $\mathrm{C}$ 采砂区影响, 悬浮泥沙浓度变化最 大; $\mathrm{b}$ 兴趣点主要受采砂强度相对较小的 $\mathrm{B}$ 采砂区影响, 悬浮泥沙浓度小幅上升; $\mathrm{c}$ 兴趣点和 $\mathrm{d}$ 兴趣点受 $\mathrm{A} 、$ $\mathrm{B}$ 采砂区的双重影响, 相较于其上游的 $\mathrm{b}$ 兴趣点, 悬浮泥沙浓度变化更大; 位于湖口的 $\mathrm{e}$ 兴趣点距离 3 个主 要采砂区虽比较远,悬浮泥沙浓度亦有所上升.

总的来说, 3 个主要采砂区对南部主湖区、河流人湖口的悬浮泥沙浓度影响很小, 其影响主要集中在采 砂区下游, 在湖流作用下, 由南向北经棠荫以西和松门山岛以北航道、人江水道一直延伸到湖口区域, 是鄱 
阳湖北湖区水体相较于南湖区一直处于高浑浊状态的重要原因.

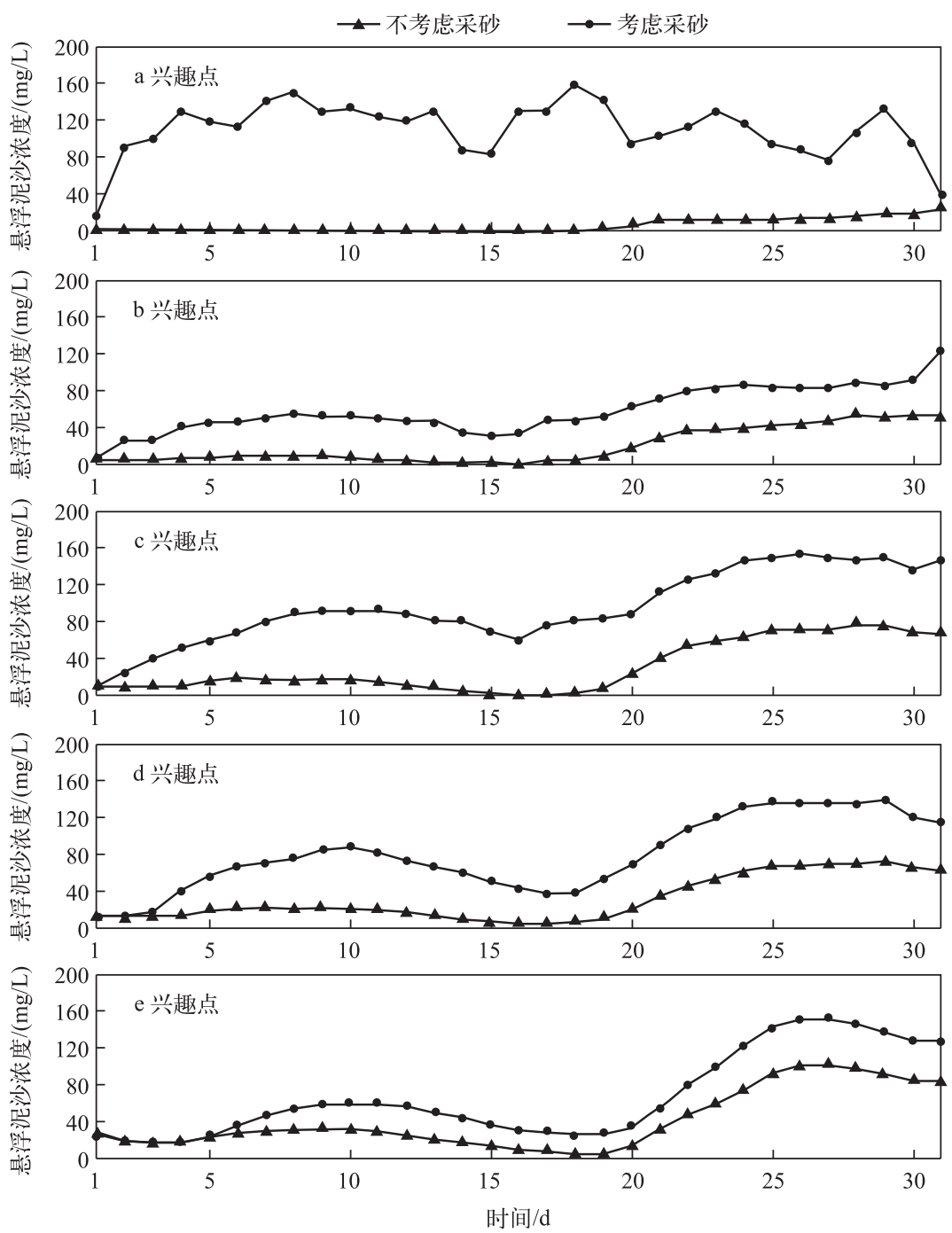

图 95 个兴趣点考虑和不考虑采砂模拟的悬浮泥沙浓度变化对比

Fig.9 Comparison of simulated suspended sediment concentration for five points of interests with and without dredging

\section{4 结语}

本文借助遥感技术和数值模拟, 针对采砂活动影响下的鄱阳湖高浑浊水体, 提出了一种利用已有的鄱 阳湖采砂区遥感监测结果、综合考虑采砂功率和采砂强度在模型中添加泥沙点源, 对采砂影响下的悬浮泥 沙进行浓度模拟的方法, 并对鄱阳湖 3 个主要采砂区的影响范围作了初步分析. 利用悬浮泥沙现场实测数 据和遥感反演结果对模拟结果进行的有效验证表明, 考虑采砂影响后, 悬浮泥沙浓度模拟值与实测值之间 $R^{2}$ 为 $0.831, R M S E$ 为 $15.5 \mathrm{mg} / \mathrm{L}$, 达到较高的精度, 其空间分布趋势与遥感反演结果趋于一致. 3 个主要采 砂区对鄱阳湖南部主湖区、河流人湖口的影响较小, 其主要影响由南向北, 经棠荫以西和松门山岛以北航 道、人江水道一直延伸到湖口区域, 是鄱阳湖北湖区高浑浊水体形成的重要原因. 研究表明, 利用此方法能 够有效考虑采砂活动影响, 提高鄱阳湖悬浮泥沙模拟精度并对采砂影响范围进行有效分析. 本文综合考虑 
模型要求和计算性能,采取较大尺寸的计算网格,不利于鄱阳湖复杂岸线边界内悬浮泥沙的高精度模拟,网 格的改进将进一步提高悬浮泥沙模拟精度. 基于现场观测资料和遥感影像确定采砂区设置了情景模拟, 对 数值模型模拟人为活动影响作了初步探索. 利用更精确的现场观测资料和遥感影像确定采砂区域、时间、强 度等, 对鄱阳湖采砂影响下的悬浮泥沙进行更高精度数值模拟, 分析悬浮泥沙时空变化机制, 是未来进一步 的研究方向.

\section{5 参考文献}

[ 1 ] 陈晓玲, 袁中智, 李艈湘等. 基于遥感反演结果的悬浮泥沙时空动动态规律研究一一以珠江河口及邻近海域为 例. 武汉大学学报:信息科学版,2005, 30(8):677-681.

[ 2 ] 陈界仁, 沙捞.巴里, 陈国祥. 二维水库水流泥沙数值模拟. 河海大学学报, 2000, 28(5):11-15.

[ 3 ] 李国胜, 王海龙, 董 超. 黄河人海泥沙输运及沉积过程的数值模拟. 地理学报, 2005, 60(5):707-716.

[ 4 ] Elias EPL, Cleveringa J, Buijsman MC et al. Field and model data analysis of sand transport patterns in Texel Tidal inlet (the Netherlands). Coastal Engineering, 2006, 53(5):505-529.

[ 5 ] Wang ZB, Tse ML, Lau SC. A study on sedimentation of tidal rivers and channels flowing into deep bay with a Delft3d model. Proceedings of the Sixth International Conference on Asian and Pacific Coasts, 2011.

[6] 陈晓玲, 吴忠宜, 田礼乔等. 水体悬浮泥沙动态监测的遥感反演模型对比分析一一鄱阳湖为例. 科技导报, 2007,25 ( 6 ) : 19-22.

[ 7 ] 陶 菲, 张 鹰, 王晶晶等. 悬浮泥沙浓度遥感反演模式研究. 海洋工程, 2007,25(4):96-101.

[ 8 ] 钱一婧. 基于遥感和数值模拟技术的河口水流及水质过程模拟研究 [学位论文]. 南京:南京师范大学,2008.

[9] 李 宁. 近岸水质的遥感监测和数值模拟研究 [学位论文]. 天津: 天津大学, 2009.

[10] 张 鹏, 陆建忠, 陈晓玲等. MODIS 遥感数据辅助的鄱阳湖水体范围变化数值模拟. 武汉大学学报: 信息科学版, 2012,37(9) : 1087-1091.

[11] Oey LY,Ezer T, Hu CM et al. Baroclinic tidal flows and inundation processes in Cook Inlet, Alaska: numerical modeling and satellite observations. Ocean Dynamics, 2007, 57(3):205-221.

[12] Feng L,Hu CM, Chen XL et al. Human induced turbidity changes in Lake Poyang between 2000 and 2010: Observations from MODIS. Journal of Geophysical Research,2012, 117( C7).

[13] 胡春华, 施 伟, 胡龙飞等. 鄱阳湖水利枢纽工程对湖区氮磷营养盐影响的模拟研究. 长江流域资源与环境, $2012,21(6): 749-755$.

[14] 赖锡军, 姜加虎, 黄 群等. 鄱阳湖二维水动力和水质耦合数值模拟. 湖泊科学, 2011, 23(6): 893-902. DOI 10. 18307/2011.0611.

[15] 李云良, 张 奇, 姚 静等. 鄱阳湖湖泊流域系统水文水动力联合模拟. 湖泊科学, 2013, 25(2) :227-235. DOI 10. 18307/2013.0208.

[16] Lin Y, Cao Q. Lake Poyang water quality model for dynamic prediction. 2012 Fourth International Conference on Computational and Information Sciences (ICCIS) IEEE, 2012: 1214-1216.

[17] 王 鹏,赖格英,黄小兰. 鄱阳湖水利枢纽工程对湖泊水位变化影响的模拟. 湖泊科学, 2014, 26(1):29-36. DOI $10.18307 / 2014.0104$.

[18］张 强, 张小峰. 采砂深度对分汉河道影响分析. 华东师范大学学报: 自然科学版,2009,(3):127-135.

[19] Hibma A, Wang ZB, Stive MJF et al. Modelling impact of dredging and dumping in ebb-flood channel systems. Transaction of Tianjin University, 2008, 14:271-281.

[20] Jeroen S. The influence of dredging activities on the morphological development of the Columbia River mouth [Thesis ]. Delft University of Technology, Department of Hydraulic Engineering Section of Coastal Engineering, 2012.

[21] 李 佳,姚炎明,孙志林等. 大型海洋倾倒区悬浮物迁移扩散的数值模拟. 浙江大学学报: 工学版, 2011, 45 (7): 1319-1328.

[22］鸟国锋, 崔丽娟. 基于遥感技术的鄱阳湖采砂对水体透明度的影响. 生态学报,2008,28(12):6113-6120.

[23] 崔丽娟, 翟彦放, 邬国锋. 鄱阳湖采砂南移扩大影响范围一一多源遥感的证据. 生态学报, 2013, 33 (11): 3520-3525.

[24] Leeuw J, Shankman D, Wu GF et al. Strategic assessment of the magnitude and impacts of sand mining in Lake Poyang, 
China. Regional Environmental Change,2009,10(2) :95-102.

[25] 张 鹏. 基于遥感的鄱阳湖悬浮泥沙数值模拟与同化研究 [学位论文]. 武汉:武汉大学, 2014.

[26] Ackerman S, Kathleen S, Menzel P et al. Discriminating clear-sky from cloud with MODIS algorithm theoretical basis document(MOD35). MODIS Cloud Mask Team, Cooperative Institute for Meteorological Satellite Studies, University of Wisconsin, 2010.

[27] Huet A, Didan K, Miura T et al. Overview of the radiometric and biophysical performance of the MODIS vegetation indices. Remote Sensing of Environment, 2002, 83(1) : 195-213.

[28] Cui LJ, Qiu Y, Fei T et al. Using remotely sensed suspended sediment concentration variation to improve management of Lake Poyang, China. Lake and Reservoir Management, 2013,29( 1 ) :47-60.

[29] Roelvink JA, Van Banning G. Design and development of DELFT3D and application to coastal morphodynamics. Hydroinformatics, 1994, 94: 451-455.

[30］唐立模, 肖 洋, 周洪都等. 赣江东西河分流比影响因素研究. 水利水运工程学报, 2011,(4):64-68.

[31] Roelvink JA, Walstra DJ. Keeping it simple by using complex models. Advances in Hydro-science and Engineering, 2004, 6: 1-11.

[32] Li J, Tian LQ, Chen XL et al. Remote-sensing monitoring for spatio-temporal dynamics of sand dredging activities at Lake Poyang in China. International Journal of Remote Sensing, 2014, 35( 16) :6004-6022.

[33] Pennekamp JGS, Epskamp RJC, Rosenbrand WF et al. Turbidity caused by dredging: viewed in perspective. Terra et Аqua, 1996, 64: 10-17. 